\title{
Clinical correlates of the restless legs syndrome
}

\author{
Correlações clínicas da síndrome das pernas inquietas \\ Luis Fabiano Marin, Andre Carvalho Felicio, William Adolfo Santos, Lucila Bizari Prado, Gilmar Fernandes Prado
}

\begin{abstract}
Objective: To determine the clinical correlates of the restless legs syndrome (RLS) in a Brazilian sleep disorders center. Methods: We retrospectively studied 118 patients with RLS from January, 2004, to December, 2010. The analyzed variables were: age at disease onset, gender, race, years of school instruction, primary and secondary RLS, and treatment options. Results: Among the studied patients, $83.9 \%$ were women with a female/male sex ratio of 5:1. Mean age of the patients at symptom onset \pm standard deviation was $41.7 \pm 17.9$ years-old. The primary RLS was found in $85 \%$ of patients. The other $15 \%$ remainders consisted of secondary forms, and they were associated with neuropathy, iron deficiency anemia, end-stage renal disease, or Parkinson's disease. Drug therapy for RLS was introduced in 67\% of patients. Conclusions: Most patients presented primary RLS with an early disease onset. Further epidemiological studies are welcomed to provide better information on secondary RLS in Brazil.
\end{abstract}

Key words: restless legs syndrome, restless legs syndrome, epidemiology, Brazil.

\section{RESUMO}

Objetivo: Determinar as correlações clínicas da síndrome das pernas inquietas (SPI) em um centro brasileiro de distúrbios de sono. Métodos: Foram estudados retrospectivamente 118 pacientes com SPI atendidos entre janeiro de 2004 e dezembro de 2010. As variáveis analisadas compreendiam: idade ao início da doença, sexo, raça, escolaridade, SPI primária e secundária e tratamento da SPI. Resultados: Do total de pacientes estudados, 83,9\% eram mulheres e a razão mulher/homem foi de 5:1. A média de idade dos pacientes \pm desvio padrão de quan-

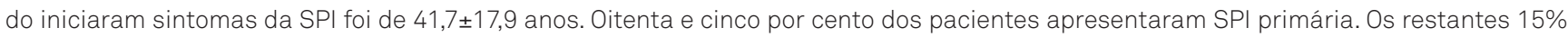
apresentaram a forma secundária, que estava associada à neuropatia periférica, anemia por deficiência de ferro, insuficiência renal crônica e doença de Parkinson. Foi introduzida medicação para SPI em 67\% dos pacientes. Conclusões: A maioria dos pacientes apresentou SPI primária com início precoce da doença. Mais estudos epidemiológicos são necessários para prover informações sobre as causas secundárias de SPI no Brasil.

Palavras-Chave: síndrome das pernas inquietas, síndrome das pernas inquietas, epidemiologia, Brasil.

The restless legs syndrome (RLS) is a neurological disorder characterized by an urgency to move the legs usually associated with unpleasant sensations in the lower limbs. The symptoms predominate at rest and at night, and they are relieved by leg movements. It may be primary (idiopathic) or secondary to diverse conditions, such as pregnancy, endstage renal disease, iron deficiency anemia, peripheral neuropathy, and Parkinson's disease ${ }^{1}$.

RLS predominates in women and its prevalence in the general population is estimated to range from 5 to $15 \%$. In Brazil, there are few clinical epidemiological studies of RLS ${ }^{2-4}$. In this context, our objective was to determine the clinical correlates of patients with RLS in a Brazilian tertiary sleep disorder center.

\section{METHODS}

A retrospective case-record analysis was performed in patients with RLS who visited the outpatient Neuro-Sono Sleep Center at the Universidade Federal de São Paulo, from January, 2004, to December, 2010. The Neuro-Sono sleep clinic attends about six new cases per week, totaling 270 new ones per year.

To be included in this study, patients had to fulfill the diagnostic criteria for RLS established by the International RLS Study Group (IRLSG)2. Basically, data collected were age at disease onset and at the time of evaluation, gender, race (white or non-white), years of school instruction, and RLS treatment.

Neuro-Sono - Division of Sleep Disorders, Department of Neurology and Neurosurgery, Universidade Federal de São Paulo (UNIFESP), São Paulo SP, Brazil. Correspondence: Luis Fabiano Marin; Rua Claudio Rossi 394; 01547-000 São Paulo SP - Brasil; E-mail: Luisfabianom@gmail.com 
We have searched for secondary causes of RLS (iron deficiency anemia, neuropathy, pregnancy, end-stage renal disease, and Parkinson's disease). We considered with iron deficiency anemia those individuals who performed complete blood count and who had a hypochromic microcytic anemia with low levels of hemoglobin $(\mathrm{Hb}<13 \mathrm{~g} / \mathrm{dL}$ for men; $\mathrm{Hb}<12 \mathrm{~g} / \mathrm{dL}$ for women). For the diagnosis of peripheral neuropathy, it was necessary to establish clinically the disease and its confirmation by electrophysiological studies. Endstage renal disease was diagnosed in patients who had creatinine clearance $<15 \mathrm{~mL} / \mathrm{min}$. or who were performing hemodialysis. Two-tailed $\chi^{2}$ test was performed to access differences between age of symptoms onset in the primary versus secondary RLS Groups. Statistical significance was set at $\mathrm{p}<0.005$.

We investigated comorbid clinical conditions, such as arterial hypertension, diabetes mellitus, hypothyroidism, depression, smoking, alcohol consumption, fibromyalgia, and other rheumatic diseases taking into account data on medical files.

The clinical data recording over the seven year-protocol was carried out in a systematic manner, using a standard clinical protocol. Even though different physicians of varying degrees of experience participated on data collection, each case on the first consultation and subsequent follow-up was obligatorily discussed with a sleep-disorder specialist, due to the academic nature of our institution. Incomplete or poorly recorded files were excluded from the statistical analysis.

This study protocol is part of a larger study on RLS, and it was approved by our local Ethical Committee (registration number=085005).

\section{RESULTS}

A total of 118 patients (women=83.9\%; men=16.1\%) fulfilled the RLS diagnostic criteria of the IRLSG. The female to male ratio was 5:1, and the mean age at evaluation was $52.4 \pm 16.4$ years-old. Most patients were white $(88 \%)$. The mean school instruction was $9 \pm 3.1$ years-old. Only one patient had no school instruction. Overall, the mean body mass index (BMI) was $26.5 \pm 5.5 \mathrm{~kg} / \mathrm{m}^{2}$.

The range for age at onset in patients with RLS was considerably wide (3 to 81 years-old) with mean age of $41.7 \pm 17.9$ years-old. Sixty-four patients (55\%) had their age at onset of RLS symptoms before 45 years-old (early-onset disease).

In $85 \%$ of the patients, we did not find secondary causes of RLS, while the remaining ones (15\%) with RLS were associated with peripheral neuropathy, iron deficiency anemia, end-stage renal disease, or Parkinson's disease (Table 1). With respect to the etiology of neuropathy in the affected individuals, seven had diabetic neuropathy and one was of unknown cause. In the group of primary RLS, the average age at onset of RLS symptoms was $41.1 \pm 17.6$ years-old, while in the group of secondary RLS, it was $45 \pm 19.3$ years-old. We did not find significant differences regarding age of symptom onset in the primary versus secondary RLS Groups ( $\mathrm{p}=0.637$ ).

Drug therapy for RLS was introduced in $67 \%$ of our patients and included: pramipexole $(n=52 ; 44 \%)$, ropinirole $(n=3 ; 2.5 \%)$, levodopa $(\mathrm{n}=5 ; 4.2 \%)$, gabapentin $(\mathrm{n}=13 ; 11 \%)$, clonazepam $(n=6 ; 5 \%)$, diazepam $(n=1 ; 0.8 \%)$, oxcarbazepine $(n=2 ; 1.7 \%)$, and carbamazepine $(n=3 ; 2.5 \%)$. In our sample, most patients were taking only one medication for symptom control, but seven required one of the following associations: pramipexol plus gabapentin, gabapentin plus clonazepam, and pramipexol plus levodopa. Particularly, the latter association was taken by our patients with Parkinson's disease (n=3; Table 1).

The most frequent clinical comorbid conditions in our sample were: arterial hypertension $(n=45 ; 38.1 \%)$, depression $(\mathrm{n}=35 ; 27.9 \%)$, hypothyroidism $(\mathrm{n}=18 ; 14.4 \%)$, diabetes $(\mathrm{n}=9$; $7.6 \%)$, and fibromyalgia $(n=6 ; 5 \%)$. Smoking was found in $5.9 \%$ of the patients (Table 2 ).

Of all patients suspected of RLS, 26 were not included in this study because they did not fulfill the diagnostic criteria established by the IRLSG.

\section{DISCUSSION}

In Brazil, there are few studies on epidemiological features of RLS. Dantas et al. studied 32 Brazilian elderly subjects and found a $15 \%$ prevalence of RLS, predominantly in females 5 . Moreover, Goffredo Filho et al. evaluated 176 patients on dialysis therapy and found a $14 \%$ frequency of RLS ${ }^{6}$. Alves et al., investigating RLS in 524 pregnant women, found a $13.5 \%$ prevalence ${ }^{7}$. Recently, Eckeli et al. interviewed 1,155 individuals in the rural town of Cassia dos Coqueiros and estimated a $6.4 \%$ RLS prevalence ${ }^{4}$.

Table 1. Secondary causes of the restless legs syndrome.

\begin{tabular}{lc} 
Causes & Number of patients/\% of patients \\
\hline Peripheral neuropathy & $8 / 6.8$ \\
Iron deficiency anemia & $6 / 5$ \\
Parkinson's disease & $3 / 2.5$ \\
End-stage renal disease & $1 / 0.8$ \\
\hline
\end{tabular}

Table 2. Comorbid conditions in patients with the restless legs syndrome.

\begin{tabular}{lc} 
Comorbid conditions & Number of patients / \% of patients \\
\hline Arterial hypertension & $45 / 38.1$ \\
Depression & $35 / 27.9$ \\
Hypothyroidism & $18 / 14.4$ \\
Diabetes mellitus & $9 / 7.6$ \\
Smoking & $8 / 5.9$ \\
Fibromyalgia & $6 / 5$ \\
\hline
\end{tabular}


Our study was performed in an outpatient center of sleep disorders, however the methodology used does not allow us to estimate prevalence or incidence rates. Even so, we demonstrated a high predominance of RLS in females and in Caucasians (attributed as white skin color herein), which is consistent with previous epidemiological data of a higher prevalence of RLS in females and Caucasians ${ }^{8}$.

Our data also disclosed a predominance of primary rather than secondary RLS, and our patients with primary RLS had an earlier disease onset (mean age: $41.1 \pm 17.6$ years-old). Literature in this issue has divided early RLS onset in those patients in whom the first symptoms began before 45 yearsold, and possibly they have a genetic and family component ${ }^{9}$. Secondary forms of RLS in our patients were associated with some conditions previously described ${ }^{1,2}$, and neuropathy was the most frequent condition (44.4\%), followed by iron deficiency anemia (33.3\%).

Regarding the presence of clinical comorbidities in our patients, we found high frequency of arterial hypertension and depression. Previous studies have suggested a relationship between RLS and arterial hypertension, but they did not find a clear association of hypertension as a risk factor for $\mathrm{RLS}^{10}$. On the other hand, epidemiological studies report a two to four risk of depressive disorder in patients with RLS compared with the healthy controls, suggesting an association between both diseases ${ }^{11}$.

Most patients in our study were taking medication to control the symptoms of RLS, suggesting a higher degree of symptom severity. However, a shortcoming of our study, due to its retrospective methodology, was the lack of graduating patients' RLS severity, alongside with a referral bias that tends to select more severe cases than in the general population.

In summary, our large series of RLS confirms the epidemiological data previously reported elsewhere for nonBrazilian and Brazilian populations and contributes to better understand regional clinical characteristics of our RLS patients.

\section{References}

1. Trenkwalder C, Paulus W, Walters AS. The restless legs syndrome. Lancet Neurol 2005;4:465-475.

2. Allen RP, Picchietti D, Hening WA, Trenkwalder C, Walters AS, Montplaisir J. Restless legs syndrome: diagnostic criteria, special considerations, and epidemiology. A report from the restless legs syndrome diagnosis and epidemiology workshop at the National Institutes of Health. Sleep Med 2003;4:101-119.

3. Grupo Brasileiro de Estudos, Sindrome das Pernas Inquietas. Síndrome das pernas inquietas: diagnóstico e tratamento. Opinião de especialistas brasileiros. Arq Neuropsiquiatr 2007;65:721-727.

4. Eckeli AL, Gitaí LL, Dach F, et al. Prevalence of restless legs syndrome in the rural town of Cassia dos Coqueiros in Brazil. Sleep Medicine 2011;12:762-767.

5. Dantas FG, Medeiros JLA, Farias KS, Riberio CD. Restless legs syndrome in institutionalized elderly. Arq Neuropsiquiatr 2008;66:328-330.
6. Goffredo Filho GS, Gorini CC, Purysko AS, Silva HC, Elias IE. Restless legs syndrome in patients on chronic hemodialysis in a Brazilian city: frequency, biochemical findings and comorbidities. Arq Neuropsiquiatr 2003;61:723-277.

7. Alves DA, Carvalho LB, Morais JF, Prado GF. Restless legs syndrome during pregnancy in Brazilian women. Sleep Med 2010; 11:1049-1054.

8. Ondo W. Epidemiology of restless legs syndrome. Sleep Med 2002;3(Suppl):S13-S15.

9. Allen RP, Earley CJ. Restless legs syndrome. A review of clinical and pathophysiologic features. J Clin Neurophysiol 2001;18:128-147.

10. Calhoun DA, Harding SM. Sleep and hypertension. Chest 2010;138:434-443.

11. Hornyak M. Depressive disorders in restless legs syndrome: epidemiology, pathophysiology and management. CNS Drugs 2010;24:89-98. 